\title{
Cardiovascular Performance Following Continuous Positive Airway Pressure in Patients with Severe Obstructive Sleep Apnea
}

\author{
Khanaphaphon Wuttiumporn PhD.candidate ${ }^{1}$, Wilaiwan Khrisanapant PhD ${ }^{1^{*}}$, \\ Orapin Pasurivong MD${ }^{1}$, Watchara Boonsawat PhD², Banjamas Intarapoka MD 3
}

${ }^{1}$ Department of Physiology, Faculty of Medicine, Khon Kaen University 40002, Thailand

${ }^{2}$ Department of Medicine, Faculty of Medicine, Khon Kaen University 40002, Thailand

${ }^{3}$ Bumrungrad International Hospital, Bangkok 10110, Thailand

\begin{abstract}
Background: Obstructive sleep apnea (OSA) may lead to decreased exercise capacity. We investigated whether continuous positive airway pressure (CPAP) treatment improved cardiovascular performance in OSA patients.

Methods: Forty healthy subjects (control group) and 40 severe OSA patients were recruited. The two groups were matched for age, gender, and body mass index. OSA patients were assigned to CPAP and non-CPAP treatment groups in equal numbers. All subjects underwent cardiopulmonary exercise testing (CPET) using a treadmill and an incremental protocol until symptom limitation (Day 0). CPET was repeated at Day 180 in the CPAP treatment group.

Results: OSA patients had lower maximal oxygen consumption $\left(\mathrm{V}^{\prime} \mathrm{O}_{2 \max }\right)(1666.3 \pm 451.3 \mathrm{vs} .1375 .6 \pm 227.7 \mathrm{ml} / \mathrm{min}, 28.2 \pm$ 5.5 vs. $18.9 \pm 3.8 \mathrm{ml} / \mathrm{min} / \mathrm{kg})(\mathrm{p}<0.001)$, higher maximal $V^{\prime} E / \mathrm{V}^{\prime} \mathrm{CO}_{2}(\mathrm{p}<0.01), V^{\prime} E / V^{\prime} \mathrm{O}_{2}(\mathrm{p}<0.001)$, heart rate (HR) reserve ( $\mathrm{m}$ $<0.001)$, and blunted HR recovery $(H R R)$ at $1-5 \mathrm{~min}(\mathrm{p}<0.001)$ compared to controls. $\mathrm{V}^{\prime} \mathrm{O}_{2 \max }$ was negatively correlated with $\mathrm{AHI}\left(\mathrm{R}^{2}=0.1363, \mathrm{p}<0.05\right)$. In the CPAP but not in non-CPAP treatment group, both $V^{\prime} \mathrm{O}_{2 \max }(p<0.05), \mathrm{HRR}(\mathrm{p}<0.001)$, and HR reserve $(p<0.05)$ were improved on Day 180 compared to Day 0.

Conclusion: Our study demonstrates that CPAP therapy for six months provides clinical benefits by improving cardiovascular performance.

Keywords: Obstructive sleep apnea, continuous positive airway pressure, cardiopulmonary exercise testing, heart rate recovery
\end{abstract}

Clinical trial registration number: TCTR20170810004

\section{INTRODUCTION}

Obstructive sleep apnea (OSA) is a chronic condition characterized by repetitive collapse of the upper airway during sleep, leading to significant hypoxemia and recurrent arousals from sleep (Vgontzas \& Kales, 1999). OSA imposes

*Correspondence: wilkhrakku.ac.th

Associate Professor Wilaiwan Khrisanapant, Department of Physiology,

Faculty of Medicine, Khon Kaen University, Khon Kaen 40002, Thailand.

Telephone 6643363263

Received: 05 September 2017 Accepted: 03 October 2017

Sleep and Hypnosis

Journal homepage:

www.sleepandhypnosis.org

ISSN:1302-1192 (Print) 2458-9101 (Online) numerous consequences on the cardiovascular system such as myocardial infarction and coronary heart disease, and without treatment, causes significant predisposition to cardiovascular disease morbidity and mortality (Shah, Yaggi, Concato, \& Mohsenin, 2010). The cardiovascular consequences of OSA may be primarily due to the intermittent hypoxia and arousals resulting from recurring apneic events (Ryan, Taylor, \& McNicholas, 2005), increase oxidative stress (Tichanon et al., 2016), and sympathetic over-activity (Santamit et al., 2015).

Cardiopulmonary exercise testing (CPET) is an important clinical tool for estimating exercise capacity and predicting outcomes in patients with cardiac conditions (Albouaini, Egred, \& Alahmar, 2007). Adults 
with untreated OSA show abnormal CPET responses compared to age-, activity-, and weight-matched controls without OSA. These abnormal CPET responses are reduced cardiorespiratory fitness $\left(\mathrm{V}^{\prime} \mathrm{O}_{2}\right)$, exaggerated systolic (SBP) and/or diastolic blood pressure (DBP), chronotropic impairment (e.g. high $\mathrm{HR}$ reserve), impaired ventilatory equivalents for oxygen $\left(V^{\prime} E / V^{\prime} \mathrm{O}_{2}\right)$, impaired ventilatory equivalents for carbon dioxide $\left(\mathrm{V}^{\prime} \mathrm{E} / \mathrm{V}^{\prime} \mathrm{CO}_{2}\right)$ at submaximal and maximal workloads, and blunt heart rate recovery (HRR) at peak exercise (Aron, Zedalis, Gregg, Gwazdauskas, \& Herbert, 2009; Grote, Hedner, \& Peter, 2004; Hargens et al., 2009; Nanas et al., 2010; Vanhecke et al., 2008). However, a few studies have reported similar $\mathrm{V}^{\prime} \mathrm{O}_{2 \text { peak' }}, \mathrm{HR}$ reserve, SBP, and DBP at peak exercise between OSA patients and controls (Alonso-Fernandez et al., 2006; Hargens et al., 2008; Kaleth et al., 2007).

Continuous positive airway pressure (CPAP) is the gold standard treatment for OSA patients. Proper CPAP use results in significant clinical benefits, such as reduced inflammation, oxidative stress, and cardio-metabolic risk (McDaid et al., 2009). The mechanism by which CPAP treatment improves cardiovascular performance during maximum exercise in OSA patients is unclear. Following two months of CPAP treatment, patients with severe OSA show increased exercise capacity (e.g. increases in $\mathrm{V}^{\prime} \mathrm{O}_{2}$, workload, and oxygen pulse at peak exercise) as well as an increase in anaerobic threshold (Lin, Lin, Wu, \& Chou, 2004). However, studies in patients with mild to moderate OSA found no beneficial effect of CPAP treatment on exercise capacity (Edward Shifflett, Walker, Gregg, Zedalis, \& Herbert, 2001; Maeder et al., 2009; Pendharkar, Tsai, Eves, Ford, \& Davidson, 2011). We therefore investigated whether the CPET responses of OSA patients were lower compared to a control group of age- and BMI-matched adults without OSA, and whether cardiovascular performance were improved following 180 days of CPAP treatment in severe OSA patients.

\section{METHODS}

\section{Study Subjects}

This study was non-randomized and open-labeled. A total of 80 subjects consisting of 40 healthy subjects and
40 severe OSA patients were included in this study. Each group had 15 males and 25 females aged 30 years or older. Forty healthy subjects (control group) with no history of OSA and Epworth Sleepiness Scale (ESS) of less than five were recruited from the healthy Thai population in Khon Kaen Province, Thailand. Subjects with a history of smoking, cardiovascular, neuromuscular, or pulmonary disease, severe microvascular diabetic complications, diabetes mellitus, hypertension (blood pressure $\geq 140 / 90$ $\mathrm{mm} \mathrm{Hg}$ ), or arthritis were excluded from the study.

Forty severe OSA patients who were newly diagnosed by medical specialists using polysomnography (PSG) within the month preceding the beginning of the study were recruited from the Sleep Disorder Clinic at Srinagarind Hospital, Khon Kaen, Thailand. OSA patients had an apnea-hypopnea index (AHI) of at least thirty events per hour and no history of treatment for OSA with CPAP or oral devices, tracheostomy, or use of oxygen therapy at home. All subjects underwent screening for medical history by a physician. Patients with a history of cardiovascular disease, autoimmune conditions, diabetes mellitus, or symptoms of respiratory tract infection in the six weeks prior to the study were excluded. Patients chose to enroll in either the CPAP treatment (CPAP group, $n=$ $20)$ or non-CPAP treatment group $(n=20)$. Patients received a general health care treatment program for OSA, including nasal spray for nasal allergies.

The purpose, benefits, and possible risks associated with the study were explained to the subjects and informed consent was obtained, in accordance with the Khon Kaen University Ethics Committee for Human Research (approval numbers HE591202).

\section{Polysomnography}

OSA patients underwent full-night PSG using a digital system at the Sleep Disorder Clinic, Faculty of Medicine (Srinagarind Hospital, Khon Kaen University). PSG was performed using a procedure described previously (Tichanon et al., 2016). Apnea was defined as a decrease in amplitude of airflow of at least $90 \%$ for at least 10 seconds and continued respiratory effort. Similarly, hypopnea was defined as a reduction in airflow of at least $30 \%$ that coincided with a decrease in oxygen 
desaturation of at least 3\% and/or the event associated with an arousal (Heinrich, Spiesshofer, Bitter, Horstkotte, \& Oldenburg, 2015). The respiratory effort-related arousal (RERA) is defined as increased respiratory effort or flattening of the nasal pressure waveform, leading to an arousal in which the sequence of breaths does not meet the criteria for hypopnea. The respiratory disturbance index (RDI) is defined as the average number of respiratory disturbances (obstructive apneas, hypopneas, and RERA) per hour (Masa et al., 2009).

\section{CPAP therapy and follow up}

CPAP (DeVilbiss IntelliPAP AutoAdjust, USA) was administered during sleep at night for at least five hours per night, for at least five days per week, and for 180 consecutive days. The patients came for a follow up visit every month, during which average hours of nightly use (h) and average days per week (days/week) of CPAP therapy for each patient were recorded from the CPAP device. The range of optimal CPAP pressure was adjusted manually each month if necessary.

\section{Cardiopulmonary exercise testing (CPET)}

All subjects (control, CPAP, and non-CPAP groups) performed an incremental exercise test on a treadmill (Stationary Cardiopulmonary exercise testing, Cosmed, Quark CPET, Italy) (Day 0). Subjects were instructed not to engage in any intense physical activity in the four hours before testing, or to consume food or caffeinated beverages in the two hours before testing (Mohammad, Dadashpour, \& Adimi, 2012). The protocol for CPET was determined based on age, weight, height, gender, and work rate (WR), according to the method described by Porszasz and colleagues (Porszasz, Casaburi, Somfay, Woodhouse, \& Whipp, 2003). The protocol used was described previously (Tichanon Promsrisuk, 2017). All tests were performed in a room in which the temperature was kept at $25^{\circ} \mathrm{C}$, according to current guidelines for exercise testing (Chest., 2003). Expired ventilation (V'E), oxygen consumption $\left(\mathrm{V}^{\prime} \mathrm{O}_{2}\right)$, carbon dioxide production $\left(\mathrm{V}^{\prime} \mathrm{CO}_{2}\right), \mathrm{ECG}$, and oxygen saturation $\left(\mathrm{SpO}_{2}\right)$ were monitored continuously and blood pressure was measured every minute. Cardiac output (CO) and stroke volume (SV) were automatically calculated via COSMED software during CPET. The test was performed under the supervision of a physician. The test was terminated in the case of dyspnea, leg fatigue, disabling symptoms, at the request of the subject, or by the investigator for safety reasons, according to previously described criteria for termination of the test (Edvardsen, Hem, \& Anderssen, 2014). HRR was defined as the difference in beats/min between $H R$ after maximal exercise $\left(H_{R_{\text {max exer }}}\right)$ and $H R$ at 1 to 5 min into recovery. Only subjects belonging to CPAP and non-CPAP groups performed CPET at Day 180.

The presence of three or more of the following criteria was used to define maximal exercise: a plateau in $\mathrm{V}^{\prime} \mathrm{O}_{2}, \mathrm{HR}$ greater than $90 \%$ of the predicted maximum $\mathrm{HR}\left(\mathrm{HR}_{\text {max-age' }}\right.$ defined as 220 - age of subject), respiratory exchange ratio (RER) of more than 1.15, request by the subject to stop because of maximal voluntary fatigue, and a score of 18 points or more on the Borg rating of perceived exertion (RPE) scale. The highest $\mathrm{V}^{\prime} \mathrm{O}_{2}$ value during 30-sec stage was used. The $\mathrm{V}^{\prime} \mathrm{O}_{2}$ plateau was defined as any two 30 -sec $\mathrm{V}^{\prime} \mathrm{O}_{2}$ values in which the second was less than or equal to the first, provided ventilation was at maximal effort (Nogueira \& Pompeu, 2006).

\section{Statistical Analyses}

Statistical analyses were performed using STATA version 13.0 (StataCorp, College Station, TX). Data were expressed as mean and standard deviation (SD). The relationship between severity of OSA (AHI) and $\mathrm{V}^{\prime} \mathrm{O}_{2 \max }$ was determined by multiple linear regressions. An unpaired t-test was used to compare OSA patients and healthy subjects with respect to anthropometric features, clinical characteristics, CPET parameters, and HRR on Day 0 . A paired T-test was used to compare CPAP parameters, CPET parameters and HRR between Day 0 and 180 of CPAP therapy in both CPAP and non-CPAP groups. A value of $p<0.05$ was considered statistically significant.

\section{RESULTS}

Table 1 shows average normal ranges of baseline demographic data in 40 controls and 40 OSA patients including 15 males and 25 females in each group. OSA 
Table 1. Baseline demographic data in controls and OSA patients (CPAP and non-CPAP treatment groups)

\begin{tabular}{|c|c|c|c|c|}
\hline & \multirow{2}{*}{$\begin{array}{l}\text { Controls } \\
(n=40)\end{array}$} & \multirow{2}{*}{$\begin{array}{l}\text { All OSA } \\
(n=40)\end{array}$} & \multicolumn{2}{|c|}{ OSA } \\
\hline & & & $\begin{array}{c}\text { CPAP } \\
(n=20)\end{array}$ & $\begin{array}{c}\text { Non-CPAP } \\
(n=20)\end{array}$ \\
\hline Age (years) & $46.9 \pm 11.2$ & $46.8 \pm 11.2$ & $45.3 \pm 10.5$ & $48.4 \pm 11.9$ \\
\hline Gender (M/F) & $15 / 25$ & $15 / 25$ & $6 / 14$ & $9 / 11$ \\
\hline Height (cm) & $162.6 \pm 8.3$ & $163.6 \pm 7.3$ & $163.9 \pm 6.2$ & $163.2 \pm 8.4$ \\
\hline Weight (kg) & $65.3 \pm 6.0$ & $69.0 \pm 10.9$ & $68.9 \pm 10.3$ & $69.0 \pm 11.8$ \\
\hline BMI $\left(\mathrm{kg} / \mathrm{m}^{2}\right)$ & $24.7 \pm 2.0$ & $25.8 \pm 3.6$ & $25.7 \pm 3.7$ & $25.9 \pm 3.7$ \\
\hline Neck circumference $(\mathrm{cm})$ & $36.9 \pm 7.1$ & $34.4 \pm 8.8$ & $34.9 \pm 3.4$ & $33.9 \pm 4.1$ \\
\hline Waist circumference $(\mathrm{cm})$ & $81.3 \pm 7.6$ & $84.6 \pm 9.4$ & $83.0 \pm 10.6$ & $86.3 \pm 7.8$ \\
\hline Hip circumference (cm) & $93.4 \pm 6.3$ & $95.2 \pm 7.2$ & $94.9 \pm 7.5$ & $95.9 \pm 7.0$ \\
\hline $\mathrm{AHI}(/ \mathrm{h})$ & $\mathrm{N} / \mathrm{A}$ & $37.8 \pm 5.8$ & $37.6 \pm 6.6$ & $37.9 \pm 5.1$ \\
\hline Epworth sleepiness scale & $2.9 \pm 1.4$ & $15.9 \pm 1.7^{\star \star \star}$ & $15.6 \pm 1.8$ & $16.2 \pm 1.5$ \\
\hline Heart rate (/min) & $80.3 \pm 9.5$ & $83.1 \pm 10.5$ & $82.7 \pm 10.1$ & $83.6 \pm 11.1$ \\
\hline Systolic BP (mm Hg) & $120.1 \pm 8.6$ & $126.4 \pm 11.2^{\star \star}$ & $124.9 \pm 10.8$ & $128.0 \pm 11.7$ \\
\hline Diastolic BP (mm Hg) & $82.3 \pm 5.5$ & $87.3 \pm 12.8^{*}$ & $90.2 \pm 11.2$ & $84.5 \pm 14.0$ \\
\hline $\operatorname{MAP}(\mathrm{mm} \mathrm{Hg})$ & $91.4 \pm 6.3$ & $100.4 \pm 10.8^{* * *}$ & $101.7 \pm 10.0$ & $99.0 \pm 11.6$ \\
\hline
\end{tabular}

Data are expressed as mean \pm SD. OSA: obstructive sleep apnea; CPAP: continuous positive airway pressure; M: male; F: female; BMI: body mass index;

AHI: apnea hypopnea index; N/A: not assessed; BP: blood pressure MAP: mean arterial pressure. ${ }^{*} p<0.05,{ }^{*} p<0.01,{ }^{* *} p<0.001$ Non-OSA vs. OSA patients.

Table 2. Polysomnographic data prior to CPAP therapy in OSA patients (CPAP and non-CPAP treatment groups)

\begin{tabular}{lcc}
\hline & $\begin{array}{c}\text { CPAP } \\
(\mathbf{n}=\mathbf{2 0})\end{array}$ & $\begin{array}{c}\text { Non-CPAP } \\
(\mathbf{n}=\mathbf{2 0})\end{array}$ \\
\hline Polysomnographic data (Day 0) & & \\
AHI (/h) & $37.6 \pm 6.6$ & $37.9 \pm 5.1$ \\
RERA (/h) & $47.2 \pm 12.6$ & $42.3 \pm 14.1$ \\
RDI (/h) & $84.8 \pm 12.1$ & $80.2 \pm 13.2$ \\
Arousal index (/h) & $57.1 \pm 16.9$ & $56.3 \pm 12.0$ \\
Apnea index (/h) & $19.5 \pm 11.1$ & $18.4 \pm 7.5$ \\
Lowest SpO $_{2}(\%)$ & $84.9 \pm 4.5$ & $83.7 \pm 4.1$ \\
\hline
\end{tabular}

Data are expressed as mean \pm SD. OSA: obstructive sleep apnea; CPAP: continuous positive airway pressure; AHI: apnea hypopnea index; RERA: respiratory effort related arousals; RDI: respiratory disturbance index; *** $<0.001$ Day 0 vs. Day 180 in CPAP treatment group.

patients had higher ESS $(p<0.001), \operatorname{SBP}(p<0.01)$, DBP ( $p$ $<0.05)$, and mean arterial pressure (MAP) $(p<0.001)$. No significant differences in these parameters between patients in CPAP (six males \& 14 females) and non-CPAP (nine males \& 11 females) treatment groups were found.

PSG data for subjects in CPAP and non-CPAP treatment groups (Day 0) and CPAP parameters for subjects in the CPAP treatment group on Day 180 are shown in Table 2. AHI, respiratory effort related arousals (RERA), respiratory disturbance index (RDI), arousal index, apnea index, and lowest $\mathrm{SpO}_{2}$ of subjects in the CPAP group did not differ from those in the non-CPAP treatment group. The average CPAP usage indices for Day
180 of $86.0 \pm 6.0 \%$, average nightly use of approximately seven hours per night indicate adequate CPAP use. The average CPAP pressure was $13.2 \pm 1.6 \mathrm{cmH}_{2} \mathrm{O}$. AHI as measured by CPAP device gradually decreased over time following CPAP treatment $(p<0.001, p<0.05)$ but no changes in other CPAP parameters were observed.

CPET parameters in controls, OSA patients, and the subgroups CPAP, and non-CPAP treatment groups at maximal exercise are shown in Table 3 and Figure 1. On Day 0 , ventilatory efficiency, as measured by $V^{\prime} E / V^{\prime} O_{2}$ and $V^{\prime} E / V^{\prime} C_{2}$, was greater in OSA patients compared to controls ( $p<0.01$ and $p<0.001$, respectively). SBP was higher while $V^{\prime} \mathrm{CO}_{2}$ was lower in OSA patients compared to controls ( $p<0.01$ and $p<0.05$, respectively). HR at maximum exercise was significantly lower in OSA patients $(p<0.001)$ and therefore HR reserve was higher $(p<$ 0.001 ) compared to controls. $\mathrm{V}^{\prime} \mathrm{O}_{2}$ max as measured in $\mathrm{ml} /$ $\min (17.4 \%), \mathrm{ml} / \mathrm{kg} / \mathrm{min}$ (32.9\%), and \%predicted 14.4\%) was significantly lower in OSA patients compared to controls $(p<0.001)$ (Figure 1).

In the CPAP treatment group, subjects showed decreased HR reserve $(p<0.001)$, increased CO ( $p<$ $0.01)$, and decreased SBP $(p<0.001)$ on Day 180 compared to Day 0 (Table 3). Interestingly, $\mathrm{V}^{\prime} \mathrm{O}_{2}$ max in $\mathrm{ml} / \mathrm{min}, \mathrm{ml} / \mathrm{kg} / \mathrm{min}$, and $\%$ predicted increased by $3.8 \%$, $3.9 \%$, and $4 \%$, respectively, after 180 days of CPAP 
Table 3. Cardiovascular responses at maximum exercise in controls and OSA patients (CPAP and non-CPAP treatment groups)

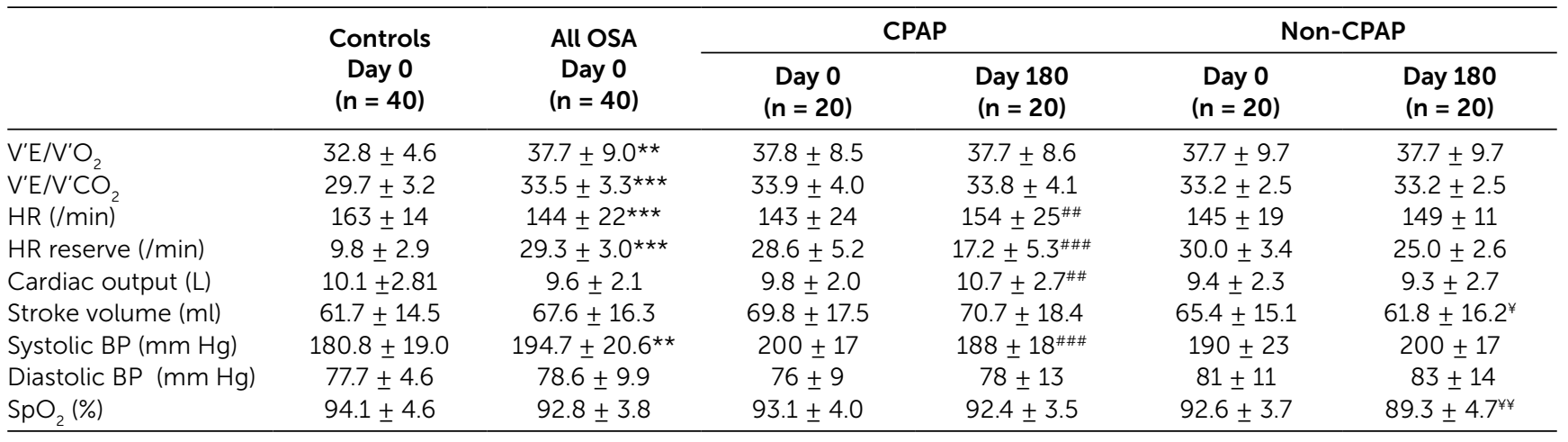

Data are expressed as mean \pm SD. OSA: obstructive sleep apnea; VE: minute ventilation; HR: heart rate; $\mathrm{BP}$ : blood pressure; SpO ${ }_{2}$ pulse oxygen saturation. ${ }^{\star \star} \mathrm{p}<0.01$, ${ }^{* * *} p<0.001$ Non-OSA vs. All OSA, ${ }^{\#} p<0.05,{ }^{\# \#} p<0.01$ pre vs. post in CPAP treatment group, ${ }^{*} p<0.05,{ }^{* *} p<0.01$ pre vs. post in non-CPAP treatment group.

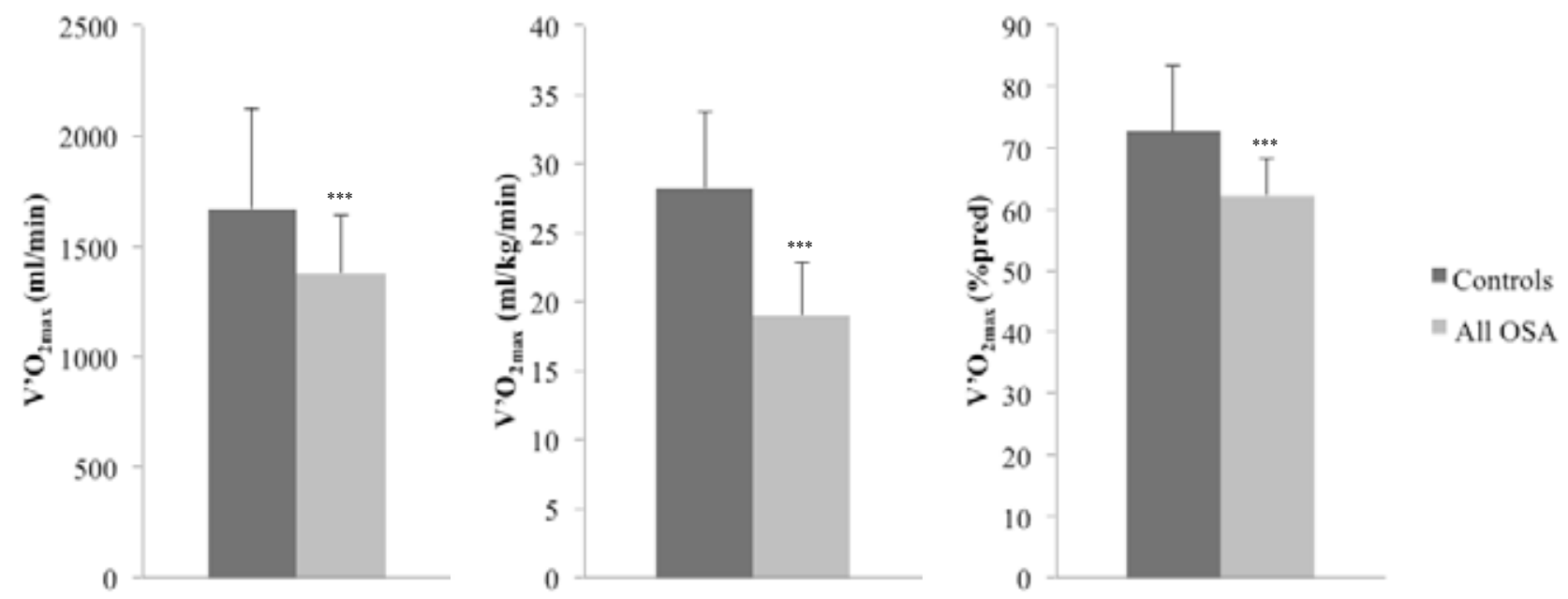

Figure 1: Maximal oxygen consumption in controls and all OSA patients. Data are expressed as mean \pm SD. *** $<0.001$ pre- versus post-CPAP therapy
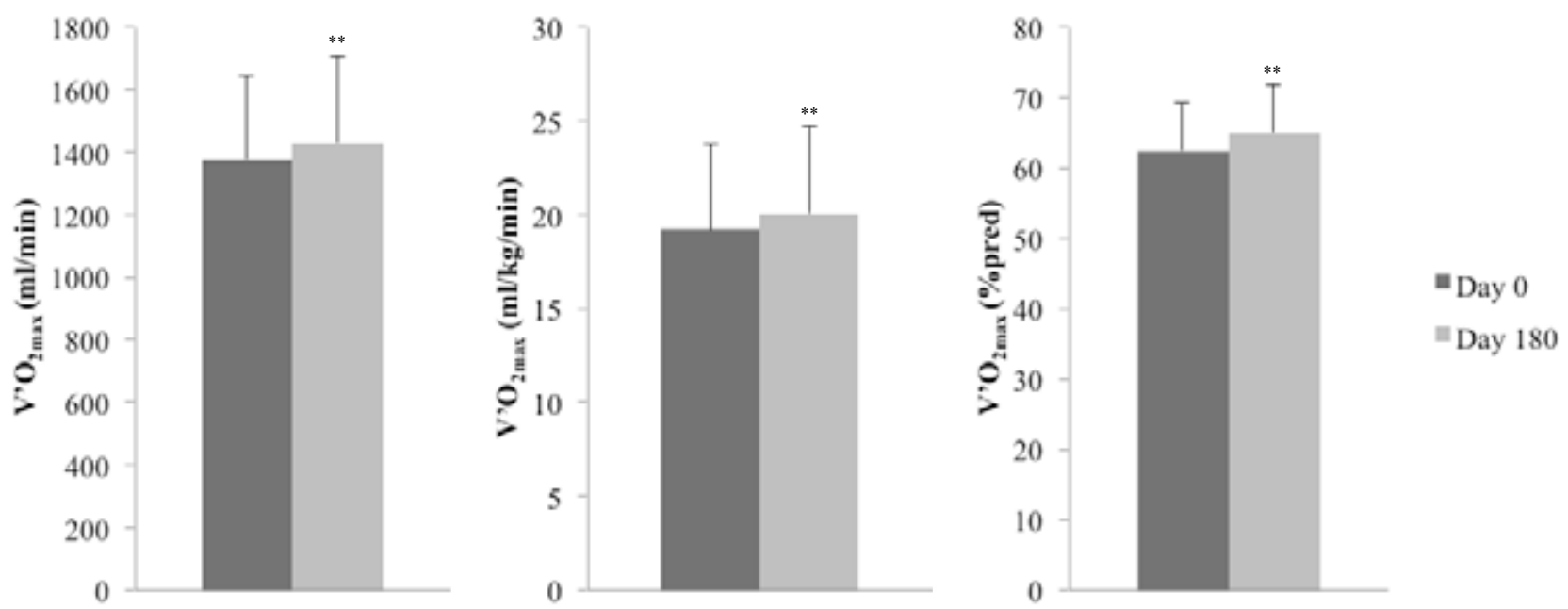

Figure 2: Maximal oxygen consumption in 20 OSA patients before and after CPAP therapy. Data are expressed as mean $\pm S D$. ${ }^{* * *} p<0.05$ pre vs. post CPAP therapy. 


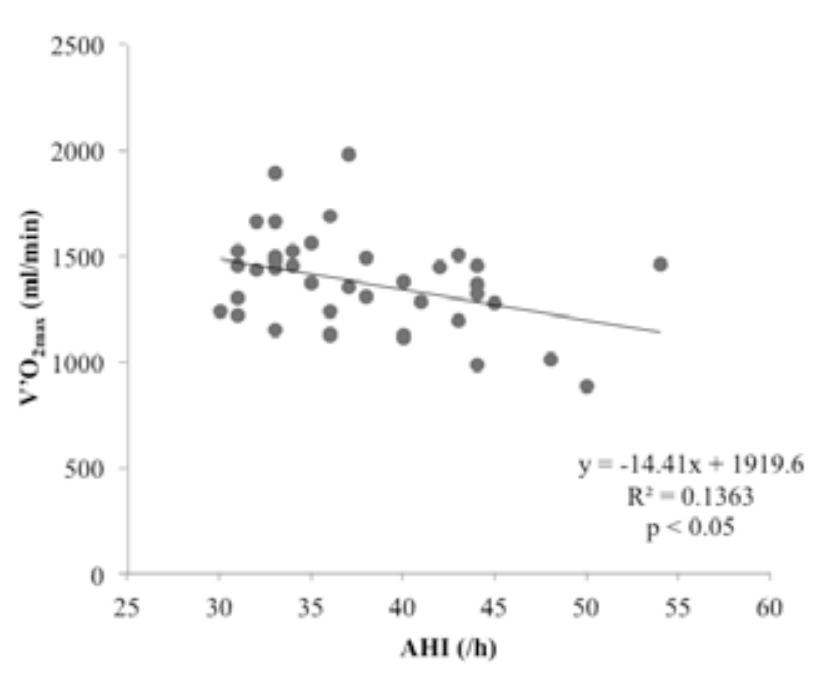

Figure 3: Association between apnea hypopnea index $(\mathrm{AHI})$ and maximal oxygen consumption $\left(\mathrm{V}^{\prime} \mathrm{O}_{2}\right)$ in 40 OSA patients.

treatment $(p<0.01)$ compared to Day 0 (Figure 2), while the non-CPAP group did not show significant changes in those values (Table 3). However, SV $(p<0.05)$ and $\mathrm{SpO}_{2}$ $(p<0.01)$ on Day 180 significantly decreased compared to Day 0 (Table 3). Linear regression analysis showed a negative correlation between $\mathrm{AHI}$ and $\mathrm{V}^{\prime} \mathrm{O}_{2 \max }\left(\mathrm{R}^{2}=\right.$ $0.1363, p<0.05$ ) (Figure 3). Moreover, AHI was negatively correlated with $\mathrm{V}^{\prime} \mathrm{O}_{2 \max }$ with age and adjusted BMI (data not shown).

Average HRR was blunted, as evidenced by higher recovery time at min 1 to 5 in OSA patients compared to controls (Table 4) ( $p$ < 0.001). Improvement in HRR after 180 consecutive days of CPAP treatment was observed ( $p$ $<0.01$ ). There were no differences in HRR between Day 0 and Day 180 in the non-CPAP group.

\section{DISCUSSION}

The main findings of this study were that (i) severe OSA patients had significantly higher SBP, DBP, and MAP at rest, significantly higher $V^{\prime} E / V^{\prime} C_{2}, V^{\prime} E / V^{\prime} O_{2}$, and $H R$ reserve, and significantly lower $\mathrm{V}^{\prime} \mathrm{O}_{2 \max }$ during maximal exercise compared to those of controls; (ii) OSA patients had blunted HRR at one to five minutes after maximum exercise compared to control group; (iii) after CPAP therapy characterized by $86 \pm 6 \%$ of CPAP usage index and $7.0 \pm 0.5 \mathrm{~h} /$ night for 180 days, significant improvements in $V^{\prime} \mathrm{O}_{2} \max , \mathrm{HR}$ reserve, HRR were observed; (iv) SV and $\mathrm{SpO}_{2}$ were preserved in CPAP treatment group, whereas they were lowered in nonCPAP group after 180 days.

The finding that OSA patients have significantly higher blood pressure in MAP at rest is in agreement with some previous studies (Kaleth et al., 2007; Nelesen et al., 1996). However, other studies found no difference in MAP between OSA patients and controls (Hargens et al., 2008; Kline et al., 2013; Tichanon et al., 2016). It is probable that this discrepancy is related to severity of OSA, with severe OSA resulting in higher MAP but mild to moderate OSA causing no measurable effect on MAP. OSA is a recognized cause of hypertension (Dopp, Reichmuth, \& Morgan, 2007). OSA episodes produce increases in SBP and DBP and hence MAP. The possible mechanisms responsible for this hypertension include intermittent hypoxemia inducing arousal (Becker et al., 2003), sympathetic overactivity (Kline et al., 2013), increased oxidative stress (4), and increased mediators of inflammation (Ryan et al., 2005). In addition, intermittent

Table 4. Heart rate recovery after maximal exercise in controls, all OSA, CPAP, and non-CPAP treatment groups at Day 0 and Day 180

\begin{tabular}{|c|c|c|c|c|c|c|}
\hline & \multirow{2}{*}{$\begin{array}{l}\text { Controls } \\
(n=40)\end{array}$} & \multirow{2}{*}{$\begin{array}{l}\text { All OSA } \\
(n=40)\end{array}$} & \multicolumn{2}{|c|}{ CPAP } & \multicolumn{2}{|c|}{ Non-CPAP } \\
\hline & & & $\begin{array}{c}\text { Day } 0 \\
(n=20)\end{array}$ & $\begin{array}{l}\text { Day } 180 \\
(n=20)\end{array}$ & $\begin{array}{c}\text { Day 0 } \\
(n=20)\end{array}$ & $\begin{array}{l}\text { Day } 180 \\
(n=20)\end{array}$ \\
\hline $\mathrm{HR}_{\text {max exer }}(/ \min )$ & $163 \pm 14$ & $144 \pm 22^{\star \star \star}$ & $143 \pm 24$ & $154 \pm 25^{\# \# \# ~}$ & $145 \pm 20$ & $150 \pm 11$ \\
\hline HRR1 (/min) & $51.5 \pm 13.5$ & $4.6 \pm 3.7^{\star \star \star}$ & $4.2 \pm 3.3$ & $18.6 \pm 8.5^{\# \# \#}$ & $5.1 \pm 4.2$ & $5.9 \pm 4.6$ \\
\hline HRR2 (/min) & $58.0 \pm 13.5$ & $10.9 \pm 4.5^{\star \star \star}$ & $10.2 \pm 4.7$ & $27.0 \pm 9.8^{\# \# \#}$ & $11.6 \pm 4.4$ & $12.3 \pm 4.2$ \\
\hline HRR3 (/min) & $69.9 \pm 15.4$ & $21.8 \pm 6.3^{\star \star \star}$ & $20.9 \pm 6.5$ & $42.0 \pm 15.7^{\# \# \#}$ & $22.7 \pm 6.1$ & $23.3 \pm 5.5$ \\
\hline HRR4 (/min) & $77.6 \pm 14.6$ & $31.8 \pm 7.2^{\star \star *}$ & $31.0 \pm 7.6$ & $51.1 \pm 15.9^{\# \# \#}$ & $32.6 \pm 6.9$ & $33.5 \pm 5.7$ \\
\hline HRR5 (/min) & $82.0 \pm 13.5$ & $36.2 \pm 8.2^{\star \star \star}$ & $35.5 \pm 8.9$ & $56.8 \pm 17.6 \# \# \#$ & $36.8 \pm 8.1$ & $38.0 \pm 7.1$ \\
\hline
\end{tabular}

Data are expressed as mean \pm SD. OSA: obstructive sleep apnea; CPAP: continuous positive airway pressure; $\mathrm{HR}_{\text {max exer; }}$ maximum heart rate during exercise; HRR: heart rate recovery. ${ }^{* \star *} p<0.001$ Non-OSA vs. OSA patients, ${ }^{\# \#} p<0.001$ pre vs. post in CPAP treatment group. 
hypoxemia also stimulates chemoreflex function, angiotensin II, and endothelin I release (Nelesen et al., 1996) which consequently leads to vasoconstriction.

We observed a significantly lower $\mathrm{V}^{\prime} \mathrm{O}_{2 \max }$ in patients with OSA compared to controls. This result agrees with previous studies (Lin et al., 2004; Nanas et al., 2010). Nevertheless, other studies found no evidence of reduced $V^{\prime} \mathrm{O}_{2 \max }$ in OSA patients (Hargens et al., 2008; Kaleth et al., 2007). Mechanisms responsible for reduced $\mathrm{V}^{\prime} \mathrm{O}_{2 \max }$ in OSA patients remain unclear. One potential contributing factor is hypoxia-induced oxidative stress, which leads to mitochondrial damage (Ryan et al., 2005) and/or decreases in number of type I fibers and mitochondria (Nanas et al., 2010), ultimately resulting in deficit in oxidative capacity (Hargens et al., 2009). In OSA patients, an increased sympathetic drive from arousal during sleep may induce increased catecholamine release during vigorous exercise (Nanas et al., 2010). Consequently, this may cause increased total peripheral resistance (Kline et al., 2013), lack of blood supply to muscle fibers, and finally a decrease in $\mathrm{V}^{\prime} \mathrm{O}_{2 \max }$ (Vanuxem et al., 1997).

In the present study, we found that sleep apnea severity index (AHI) was negatively correlated with $\mathrm{V}^{\prime} \mathrm{O}_{2 \max }$. To our knowledge, there was one study done in mild OSA patients only (Przybylowski et al., 2007), while the present study and other studies were conducted in severe or moderate to severe OSA patients (Cintra et al., 2009; Vanhecke et al., 2008). This discrepancy is probably due to differences in the severity of OSA patients included in each study.

The higher $V^{\prime} E / V^{\prime} C O_{2}$ and $V^{\prime} E / V^{\prime} O_{2}$ found in the OSA patients during maximal exercise were due to lowered $\mathrm{V}^{\prime} \mathrm{CO}_{2}$, lowered $\mathrm{V}^{\prime} \mathrm{O}_{2}$, and a slight but not significant increase in V'E compared to controls. This finding is in agreement with a previous study (Hargens et al., 2009). However, other studies reported similar V'E/V'CO $\mathrm{CO}_{2}$ and $V^{\prime} E / V^{\prime} \mathrm{O}_{2}$ at maximal exercise compared to OSA patients (Innocenti Bruni, Gigliotti, \& Scano, 2012; Kline et al., 2013; Lin et al., 2004). The higher $\mathrm{V}^{\prime} E / \mathrm{V}^{\prime} \mathrm{CO}_{2}$ and $\mathrm{V} ' \mathrm{E} /$ $\mathrm{V}^{\prime} \mathrm{O}_{2}$ during maximal exercise might be due to sympathetic activity-induced increase ventilation drive (Kaleth et al., 2007) and mitochondrial dysfunction
(Nanas et al., 2010; Ryan et al., 2005). The latter then promotes anaerobic metabolism (Hargens et al., 2009), leading to stimulating ventilation via carotid body chemoreceptors and ventilation.

We also found lower HR and hence higher HR reserve at maximal exercise in OSA patients compared to controls, which is in agreement with another study in OSA patients showing a lower average HR across all levels of exercise, including maximal exercise (Kaleth et al., 2007). In contrast, other studies observed that OSA patients had similar HR at maximal exercise intensity to controls (Kline et al., 2013; Nanas et al., 2010). This disagreement may be due to the fact that their studies were done in patients with mild to moderate OSA, while this study was carried out in patients with severe OSA. Sleep fragmentation and hypoxia cause autonomic dysfunction and ventricular dysfunction (Kaleth et al., 2007), both of which induce exercise tolerance limitation and early occurrence of dyspnea and limb muscle fatigue, and therefore the lower $\mathrm{V}^{\prime} \mathrm{O}_{2 \max }$ found in the present study (Przybylowski et al., 2007; Quadri et al., 2017). One potential consequence is that $\beta$-adrenergic receptors are down regulated, resulting in an inability to elevate HR sufficiently to quickly meet the physiological demands imposed by exercise, and finally an increase in HR reserve (Kaleth et al., 2007).

Another noteworthy observation made in our study was the delayed HRR after maximal exercise in severe OSA patients compared to controls, which is consistent with previous observations (Grote et al., 2004; Kline et al., 2013; Nanas et al., 2010). One previous study failed to find a blunted HRR to exercise in OSA patients in mild OSA patients (Hargens et al., 2008). The blunted HRR we observed in severe OSA patients could be due to an abnormal parasympathetic activity (Grote et al., 2004; Kline et al., 2013; Nanas et al., 2010) and/or autonomic imbalance (Santamit et al., 2015).

The present study showed significant improvements in $\mathrm{V}^{\prime} \mathrm{O}_{2 \max }$ and $\mathrm{CO}$ in OSA patients following 180 days of CPAP treatment. Previous studies have demonstrated that CPAP treatment for 60 to 180 days improved exercise capacity, as reflected by an increase in $\mathrm{V}^{\prime} \mathrm{O}_{2 \max }$ and maximum workload (Lin et al., 2004; Maeder et al., 2009; Quadri et al., 2017). However, another study found no 
evidence of increased $\mathrm{V}^{\prime} \mathrm{O}_{2 \max }$ following CPAP treatment for 90 days (Pendharkar et al., 2011). A possible explanation for the increased $\mathrm{V}^{\prime} \mathrm{O}_{2}$ observed in the present study is that CPAP reduces oxidative stress and inflammation leading to improving cardiac function, as evidenced by increased CO after 180 days of CPAP treatment.

Oxygen consumption is regulated by three mechanisms: $V^{\prime} \mathrm{E}, \mathrm{CO}$, and mitochondrial metabolism (Chest, 2003). Cardiovascular function is the major limiting factor for exercise in OSA patients, as opposed to impairment of ventilation or ventilatory responses to exercise (Evans, Selvadurai, Baur, \& Waters, 2014). Impaired CO response to an exercise stress test may also be a consequence of intermittent hypoxia during sleep. This study found significant improvements in $\mathrm{V}^{\prime} \mathrm{O}_{2 \max }$ of approximately $4 \%$ after treatment with CPAP therapy for 180 days. Moreover, it is likely that CPAP therapy improves CO (Quadri et al., 2017) and metabolism in mitochondria of muscle cells (Kline et al., 2013). Longitudinal research is needed to evaluate the effect of CPAP on $V^{\prime} \mathrm{O}_{2 \max }$ and cardiovascular adaptation in OSA patients.

In this study, we administered CPAP for 180 days and measured $H R$ reserve at maximal exercise before and after CPAP treatment. HR reserve improvement resulting from CPAP therapy is an effective treatment for sympathetic overactivity (Quadri et al., 2017; Santamit et al., 2015) and oxidative stress (Tichanon et al., 2016). CPAP therapy is also effective in increasing HR at maximal exercise. The improved HR reserve at maximal exercise observed was possibly due to CPAP reducing or eliminating episodes of apnea and arousal.

\section{References}

Albouaini, K., Egred, M., \& Alahmar, A. (2007). Cardiopulmonary exercise testing and its application. Postgraduate Medical Journal, 83(985), 675-682. doi: 10.1136/hrt.2007.121558

Alonso-Fernandez, A., Garcia-Rio, F., Arias, M. A., Mediano, O., Pino, J. M., Martinez, I., \& Villamor, J. (2006). Obstructive sleep apnoea-hypopnoea syndrome reversibly depresses cardiac response to exercise. European Heart Journal, 27(2), 207-215. doi: 10.1093/eurheartj/ehi621
This study also demonstrated improvement in HRR in severe OSA patients after 180 days of CPAP therapy, which agrees with the majority of other studies (Maeder et al., 2009; Quadri et al., 2017). CPAP therapy is effective in suppressing sympathetic nerve activity (Santamit et al., 2015) and improved chronotropic control during exercise (Quadri et al., 2017). Adequate CPAP use (approximately seven hours per night) in OSA patients resulted in improved HRR.

\section{CONCLUSIONS}

The present study found clinical benefits of adequate CPAP use (usage index of $86 \pm 6 \%$ and $7.0 \pm 0.5 \mathrm{~h} / \mathrm{night}$ for six consecutive months) in treating severe OSA patients, as evidenced by improved cardiovascular performance. We found increased oxygen capacity, increased cardiac output, decreased SBP, improved HRR, and improved $H R$ reserve.

\section{Acknowledgements}

This study received an Invitation Research Grant (IN59311) from the Faculty of Medicine and a Research Grant from Graduate School, Khon Kaen University. The authors would like to thank the OSA patients who participated in the present study and the nursing team at the Chest Unit, Srinakarind Hospital, Faculty of Medicine, and Khon Kaen University. We would like to acknowledge Dr. Justin Thomas Reese for editing this manuscript via the Publication Clinic, Khon Kaen University, Thailand.

\section{Conflicts of Interest}

The authors do not declare any conflict of interest.
Aron, A., Zedalis, D., Gregg, J. M., Gwazdauskas, F. C., \& Herbert, W. G. (2009). Potential clinical use of cardiopulmonary exercise testing in obstructive sleep apnea hypopnea syndrome. International Journal of Cardiology, 132(2), 176-186. doi: 10.1016/j.ijcard.2008.11.014

Becker, H. F., Jerrentrup, A., Ploch, T., Grote, L., Penzel, T., Sullivan, C. E., \& Peter, J. H. (2003). Effect of nasal continuous positive airway pressure treatment on blood pressure in patients with obstructive sleep apnea. Circulation, 107(1), 68-73. 
Chest., A. T. S. a. A. C. O. (2003). ATS/ACCP Statement on cardiopulmonary exercise testing. American Journal of Respiratory and Critical Care Medicine, 167(2), 211-277. doi: 10.1164/rccm.167.2.211

Cintra, F., Poyares, D., Rizzi, C. F., Risso, T. T., Skomro, R., Montuori, E., Tufik, S. (2009). Cardiorespiratory response to exercise in men and women with obstructive sleep apnea. Sleep Medicine, 10(3), 368-373. doi: 10.1016/j.sleep.2008.04.006

Dopp, J. M., Reichmuth, K. J., \& Morgan, B. J. (2007). Obstructive sleep apnea and hypertension: mechanisms, evaluation, and management. Current Hypertension Reports, 9(6), 529-534.

Edvardsen, E., Hem, E., \& Anderssen, S. A. (2014). End Criteria for Reaching Maximal Oxygen Uptake Must Be Strict and Adjusted to Sex and Age: A Cross-Sectional Study. PLOS ONE, 9(1), e85276. doi: 10.1371/journal.pone.0085276

Edward Shifflett, D., Walker, E. W., Gregg, J. M., Zedalis, D., \& Herbert, W. G. (2001). Effects of short-term PAP treatment on endurance exercise performance in obstructive sleep apnea patients. Sleep Medicine, 2(2), 145-151. doi: http://dx.doi. org/10.1016/S1389-9457(00)00070-8

Evans, C. A., Selvadurai, H., Baur, L. A., \& Waters, K. A. (2014). Effects of obstructive sleep apnea and obesity on exercise function in children. Sleep, 37(6), 1103-1110. doi: 10.5665/sleep.3770

Grote, L., Hedner, J., \& Peter, J. H. (2004). The heart rate response to exercise is blunted in patients with sleep-related breathing disorder. Cardiology, 102(2), 93-99. doi: 10.1159/000077911

Hargens, T. A., Guill, S. G., Aron, A., Zedalis, D., Gregg, J. M., Nickols-Richardson, S. M., \& Herbert, W. G. (2009). Altered ventilatory responses to exercise testing in young adult men with obstructive sleep apnea. Respiratory Medicine, 103(7), 1063-1069. doi: 10.1016/j.rmed.2009.01.010

Hargens, T. A., Guill, S. G., Zedalis, D., Gregg, J. M., NickolsRichardson, S. M., \& Herbert, W. G. (2008). Attenuated heart rate recovery following exercise testing in overweight young men with untreated obstructive sleep apnea. Sleep, 31(1), 104-110.

Heinrich, J., Spiesshofer, J., Bitter, T., Horstkotte, D., \& Oldenburg, O. (2015). Implications of revised AASM rules on scoring apneic and hypopneic respiratory events in patients with heart failure with nocturnal Cheyne-Stokes respiration. Sleep Breath, 19(2), 489-494. doi: 10.1007/s11325-014-1014-9

Innocenti Bruni, G., Gigliotti, F., \& Scano, G. (2012). Obstructive sleep apnea (OSA) does not affect ventilatory and perceptual responses to exercise in morbidly obese subjects. Respiratory Physiology and Neurobiology, 183(3), 193-200. doi: 10.1016/j. resp.2012.06.029

Kaleth, A. S., Chittenden, T. W., Hawkins, B. J., Hargens, T. A., Guill, S. G., Zedalis, D. \& Herbert, W. G. (2007). Unique cardiopulmonary exercise test responses in overweight middle-aged adults with obstructive sleep apnea. Sleep Medicine, 8(2), 160-168. doi: 10.1016/j.sleep.2006.08.005

Kline, C. E., Crowley, E. P., Ewing, G. B., Burch, J. B., Blair, S. N., Durstine, J. L. \& Youngstedt, S. D. (2013). Blunted heart rate recovery is improved following exercise training in overweight adults with obstructive sleep apnea. International Journal of Cardiology, 167(4), 1610-1615. doi: 10.1016/j.ijcard.2012.04.108

Lin, C.-C., Lin, C.-K., Wu, K.-M., \& Chou, C.-S. (2004). Effect of Treatment by Nasal CPAP on Cardiopulmonary Exercise Test in ObstructiveSleep Apnea Syndrome. Lung, 182(4), 199-212. doi: 10.1007/s00408-004-2502-7

Maeder, M. T., Ammann, P., Münzer, T., Schoch, O. D., Korte, W., Hürny, C. \& Rickli, H. (2009). Continuous positive airway pressure improves exercise capacity and heart rate recovery in obstructive sleep apnea. International Journal of Cardiology, 132(1), 75-83. doi: http://dx.doi.org/10.1016/j.ijcard.2007.10.040
Masa, J. F., Corral, J., Teran, J., Martin, M. J., Disdier, C., Rubio, M. \& Montserrat, J. M. (2009). Apnoeic and obstructive nonapnoeic sleep respiratory events. European Respiratory Journal, 34(1), 156-161. doi: 10.1183/09031936.00160208

McDaid, C., Duree, K. H., Griffin, S. C., Weatherly, H. L., Stradling, J. R., Davies, R. J. \& Westwood, M. E. (2009). A systematic review of continuous positive airway pressure for obstructive sleep apnoea-hypopnoea syndrome. Sleep Medicine Review, 13(6), 427-436. doi: 10.1016/j.smrv.2009.02.004

Mohammad, M. M., Dadashpour, S., \& Adimi, P. (2012). Predicted values of cardiopulmonary exercise testing in healthy individuals (a pilot study). Tanaffos, 11(1), 18-25.

Nanas, S., Sakellariou, D., Kapsimalakou, S., Dimopoulos, S., Tassiou, A., Tasoulis, A. \& Roussos, C. (2010). Heart rate recovery and oxygen kinetics after exercise in obstructive sleep apnea syndrome. Clinical Cardiology, 33(1), 46-51. doi: 10.1002/clc. 20707

Nelesen, R. A., Dimsdale, J. E., Mills, P. J., Clausen, J. L., Ziegler, M. G., \& Ancoli-Israel, S. (1996). Altered cardiac contractility in sleep apnea. Sleep, 19(2), 139-144.

Nogueira, F. S., \& Pompeu, F. A. (2006). [Maximal workload prediction models in the clinical cardio-pulmonary effort test]. Arquivos Brasileiros de Cardiologia, 87(2), 137-145.

Pendharkar, S. R., Tsai, W. H., Eves, N. D., Ford, G. T., \& Davidson, W. J. (2011). CPAP increases exercise tolerance in obese subjects with obstructive sleep apnea. Respiratory Medicine, 105(10), 1565-1571. doi: http://dx.doi.org/10.1016/j.rmed.2011.06.007

Porszasz, J., Casaburi, R., Somfay, A., Woodhouse, L. J., \& Whipp, B. J. (2003). A treadmill ramp protocol using simultaneous changes in speed and grade. Medicine and Science in Sports and Exercise, 35(9), 1596-1603. doi: 10.1249/01.mss.0000084593.56786.da

Promsrisuk, T., Khrisanapant, W., Pasurivong, O., Boonsawat, W., Patjanasoontorn, B. \& Pussadhamma, B. (2017). Equations to predict maximal oxygen consumption during cardiopulmonary exercise testing in healthy Thai adults. Gazzetta Medica Italiana Archivio per le Scienze Mediche, In-press.

Przybylowski, T., Bielicki, P., Kumor, M., Hildebrand, K., MaskeyWarzechowska, M., Korczynski, P., \& Chazan, R. (2007). Exercise capacity in patients with obstructive sleep apnea syndrome. Journal of Physiology and Pharmacology, 58 Suppl 5(Pt 2), 563-574.

Quadri, F., Boni, E., Pini, L., Bottone, D., Venturoli, N., Corda, L., \& Tantucci, C. (2017). Exercise tolerance in obstructive sleep apnea-hypopnea (OSAH), before and after CPAP treatment: Effects of autonomic dysfunction improvement. Respiratory Physiology and Neurobiology, 236, 51-56. doi: https://doi. org/10.1016/j.resp.2016.11.004

Ryan, S., Taylor, C. T., \& McNicholas, W. T. (2005). Selective activation of inflammatory pathways by intermittent hypoxia in obstructive sleep apnea syndrome. Circulation, 112(17), 26602667. doi: 10.1161/circulationaha.105.556746

Santamit, S., Khrisanapant, W., Ishida,W., Pasurivong,O., Boonsawat, W., Intarapoka, B., \& Zaeoue, W. (2015). Heart Rate Variability in Thai Patients with Obstructive Sleep Apnea. Srinagarind Medical Journal, 30(5), 518-526.

Shah, N. A., Yaggi, H. K., Concato, J., \& Mohsenin, V. (2010). Obstructive sleep apnea as a risk factor for coronary events or cardiovascular death. Sleep Breath, 14(2), 131-136. doi: 10.1007/s11325-009-0298-7

Tichanon, P., Wilaiwan, K., Sopida, S., Orapin, P., Watchara, B., \& Banjamas, I. (2016). Effect of Continuous Positive Airway Pressure on Airway Inflammation and Oxidative Stress in Patients with Obstructive Sleep Apnea. Canadian Respiratory Journal, 2016, 3107324. doi: 10.1155/2016/3107324 
Vanhecke, T. E., Franklin, B. A., Zalesin, K. C., Sangal, R. B., deJong, A. T., Agrawal, V., \& McCullough, P. A. (2008). Cardiorespiratory fitness and obstructive sleep apnea syndrome in morbidly obese patients. Chest, 134(3), 539-545. doi: 10.1378/ chest.08-0567
Vanuxem, D., Badier, M., Guillot, C., Delpierre, S., Jahjah, F., \& Vanuxem, P. (1997). Impairment of muscle energy metabolism in patients with sleep apnoea syndrome. Respiratory Medicine, 91(9), 551-557.

Vgontzas, A. N., \& Kales, A. (1999). Sleep and its disorders. Annual Review of Medicine, 50, 387-400. doi: 10.1146/annurev. med.50.1.387 